\title{
Positive reappraisal of stressful situations by children of younger school age
}

\section{KEYWORDS}

stress, negative emotions, positive emotions, benefits of stressful situations, positive reappraisal of difficult situations, individual's cognitive appraisal (primary and secondary), coping with stress, children of younger school age

\begin{abstract}
Cywińska Małgorzata, Positive reappraisal of stressful situations by children of younger school age. Kultura Społeczeństwo - Edukacja nr 1(13) 2018, Poznań 2018, pp. 63-70, Adam Mickiewicz University Press. ISSN 23000422. DOI 10.14746/kse.2018.13.4.
\end{abstract}

Stress as an individual phenomenon is a specific kind of emotional experience usually associated with negative emotions and analysed in their context. However, under certain circumstances stress may also trigger positive emotions; analysing a stressful situation and reflecting upon it may lead one to perceive benefits of stressful experience and undertake positive reappraisal of encountered difficulties. The author's own empirical research reveals that a considerable percentage of children finishing their early-stage school education believe that it is possible to find something advantageous, good and positive in stressful situations full of negative emotions. Examples of such positive aspects of stress given by those children indicate that for some of them the developmental process that involves coping with difficult situations has already started. The children begin to act independently (analyse the difficult situation, talk about it, ask questions, check the effectiveness of strategies) in order to overcome difficulties and find their meaning in human existence.

\section{Introduction}

The contemporary world is dominated by events that arouse various emotions and result in stressful situations. Postmodernism, a new phenomenon of the 21 st century, is in itself a source of stress in our lives. It is characterized by the category 
of difference, multiple discourses, varied paradigms that define the world in various different manners, and lack of generally acceptable universum (absence of core values). This ambiguity and vagueness of the surrounding reality, filled with competition that antagonizes interpersonal relations, results in numerous stress spaces, not only in the world of adults but also among children (Melosik, 2003: 459-463; 1995: 20-21; Śliwerski, 2004: 358-376). Postmodern children have very different childhoods. In the world around us we can see both 'low quality' children (homeless, poor, living in the streets) and 'high quality' children - well-invested, educated in elite schools, who function according to their parents' programme and are being trained for success (Nyczaj-Dragg, 2005: 145-148). The lives of children from both those categories may be full of stress. Coping with shortfalls and poverty triggers many stressful situations, yet striving to meet the expectations of adults who want their children to go from success to success may also be a dangerous stressor capable of disturbing the child's emotional, social, intellectual and somatic development.

There are three tendencies that can be distinguished in characterizing stress. The first tendency is to analyse stress as an external stimulus, situation, or event having certain specific qualities. The second tendency is to accentuate internal human reactions, particularly emotional reactions forming one's specific inner experience. The third tendency is to define stress as a relation between external factors and human properties (Heszen-Niejodek, 2000: 467). In all the described approaches, stress is perceived as a specific form of emotional experience.

Modern foreign psychology most often refers to the transactional theory of stress developed by Richard S. Lazarus and Susan Folkman. The fundamental notions of that theory - transaction, cognitive appraisal (primary and secondary), coping with stress - are strongly determined by emotions, usually intense and negative ones. It should be emphasized, however, that positive emotions may also occur in the stress transaction, as will be presented in the transactional theory of stress referred to above.

An example may be one of the main notions of the transactional stress theory already listed above, i.e. individual cognitive appraisal, involving mainly negative emotions but not entirely devoid of positive ones. Thus, the following emotions are involved in the primary appraisal of a given situation by an individual:

- anger, sorrow, sadness - when the situation is evaluated as harm/loss;

- fear/anxiety, worry - when the stress transaction is evaluated as a threat;

- hope, zeal, excitement, amusement - when a given situation is perceived as a challenge. 
According to this theory, the primary cognitive appraisal decides about emotions, i.e. about the intensity and nature of emotional response, and about triggering the secondary cognitive appraisal. If a transaction (relation) of an individual with the environment is evaluated as stressful, then the secondary appraisal follows in which the individual evaluates the possibilities of undertaking action aimed to eliminate the reasons for stress and activates own coping resources. It should be underlined that the coping process is in itself the source of emotions. The effectiveness of emotional control in the coping process defines its course and results. If the coping activity is successful, positive emotions are generated; on the other hand, failure gives rise to negative emotions.

In the model of Richard S. Lazarus and Susan Folkman, emotions are secondary to cognitive appraisal and change along with that appraisal. They also alter the way in which the situation is perceived. However, it should be noted that the latest results of longitudinal studies conducted by Irena Heszen have revealed that the opposite is also possible, i.e. emotions can shape the cognitive appraisal of an individual; they may be the first signal that something important is going on in a person's life and make that person undertake cognitive appraisal under the influence of emotions connected with a given situation (Heszen, 2013: 27-40).

\section{Positive emotions in stressful situations and benefits of such situations perceived by children of younger school age}

Over the recent years, many studies have been carried out in contemporary psychology to demonstrate the significance of positive emotions in stressful situations. Certain elements of that trend were present in the concept of R.S. Lazarus and S. Folkman connected with the primary appraisal related to a transaction with the environment treated as a challenge, which was demonstrated to be associated with hope, excitement and amusement.

However, it was Susan Folkman (Folkman, 1997: 1207-1221) that attached importance to positive emotions. Together with Judith Moskowitz, Folkman concentrated her attention on "meaning-focused coping”, reflecting the search for positive meaning in stressful situations and finding it, treated by both researchers as the third function of coping apart from the instrumental, problem-centred function and the self-regulation function of emotional control. The authors accentuate two levels of reappraising meaning: the global one, related to fixed values and beliefs of an individual and the situational one, connected with a specific situation and close-range goals. 
Meaning-focused coping is analysed in relation to the following forms:

- rearranging priorities when confronted with stress in order to make them more attainable, which offers a chance to achieve current goals;

- adaptive transformation of goals - revising the possibility of attaining previously set goals, giving up impossible goals and setting goals that are possible to attain;

- finding benefits in stressful experience (such as becoming a stronger and better person after traumatic experience);

- recalling benefits previously found in stressful situations experienced in the past;

- infusing ordinary events with positive meaning (e.g. being offered words of kindness from a friend, watching the beauty of nature);

- reinforcement of positive affect by initiating positive events meant to free one from emotional discomfort (e.g. spending time with friends).

Positive emotions play the adaptive role here; not only are they provoked, maintained and intensified, but they retroact on all the coping functions (emotions-focused, problem-focused and meaning-focused). Positive emotions offer a distraction from the stressor, are a source of momentary relief, and serve the purpose of replenishing physiological and social resources. They serve as a coping behaviour motive and mark the aim of that behaviour (Heszen, 2013: 48-55).

I. Heszen also presents the coping processes - emphasized by R.S. Folkman and J. Moskowitz - that inspire positive emotions. These are: positive reappraisal, problem-focused coping, creating positive events and infusing ordinary events with positive affect. Positive reappraisal consists in cognitive transformation of a stressful situation in such a way so as to be able to find its positive aspects. For that purpose we can use certain strategies, treating a stressful situation as:

- an opportunity for personal development, acquiring wisdom, patience;

- the grounds for learning important life skills;

- experience that helps us appreciate the value of life;

- a space to strengthen faith and spirituality and improve our relations with other people.

While positive reappraisal mainly takes place in the cognitive sphere, problem-focused (goal-oriented) coping relates to the behavioural sphere. As already mentioned above, it is one of the two functions of coping. Searching for positive emotions appears quite controversial in situations when the source of stress cannot be eliminated (e.g. terminal illness); still, even in such situations, as S. Folkman demonstrates, it is possible to feel positive emotions (for instance relief when we managed to alleviate the pain of a suffering person). Problem-focused coping also 
generates positive emotions in situations when we achieve positive results of undertaken activation efforts, e.g. sense of being efficient, masterly, in control, high self-esteem and in the context of activities undertaken for another person - when we receive positive reinforcement from our social environment (external reinforcement) and from the sense of fulfilled duty (internal reinforcement).

The emotional state can also be improved by creating positive events and infusing ordinary occurrences with positive affect. The former strategy involves activities deliberately undertaken to get out of the stress space (by socializing with friends, going to the cinema or theatre), while the latter is about reappraisal of ordinary everyday situations (Heszen, 2013: 88-91).

One of the forms of meaning-focused coping mentioned above, i.e. finding benefits in stressful situations, was related in a research study to children of younger school age (aged 8 and 9). This particular line of research on stressful situations forms an element of broader research on child stress ${ }^{1}$. In the research study, the method of diagnostic survey was used, and the main research techniques were questionnaire and free interview. The study involved 280 children finishing their early school education (eight- and nine-year-olds; 147 girls and 133 boys). The survey research was conducted in a specific manner; it was carried out in stages and always in the presence of the researcher who was reading out the survey questions to the children and answered their individual questions. Another technique was the free interview carried out for 70 children randomly selected from the group of research subjects. The interview was carried out to deepen the qualitative aspect of the research and penetrate the child's psychology in the context of stressful situations. The children were asked the following question: "Is it possible to find something beneficial/good/positive in stressful situations filled with negative emotions such as fear/anxiety, sadness or anger?". The children's answers to that question are presented in Table 1. As can be seen, a considerable percentage of children gave the affirmative answer. At the same time it turned out that neither sex nor age was the factor differentiating their opinions, as the chi-square test result is not statistically significant (sex: $\mathrm{p}=0.77614$; age: $\mathrm{p}=0.62330$ ).

The way in which the children answered the question is a very positive manifestation that I associate with perceiving a stressful situation as a chance to cope, not only in the classical way (by overcoming the problem and the emotions) but also by skilfully working through the situation and gaining positive experience or making a discovery.

\footnotetext{
1 - This research was presented in the following publication: Cywińska 2017.
} 
Table 1. Finding benefits of stressful experience by children $(\mathrm{N}=280)$

\begin{tabular}{|c|c|c|c|c|c|c|c|c|c|c|}
\hline \multirow{2}{*}{ Answers } & \multicolumn{2}{|c|}{ Girl } & \multicolumn{2}{|c|}{ Boy } & \multirow{2}{*}{$\begin{array}{c}\text { Total } \\
\mathrm{N}\end{array}$} & \multicolumn{2}{|c|}{ Age: 8 years } & \multicolumn{2}{|c|}{ Age: 9 years } & \multirow{2}{*}{$\frac{\text { Total }}{\mathrm{N}}$} \\
\hline & $\mathbf{N}$ & $\%$ & $\mathbf{N}$ & $\%$ & & $\mathbf{N}$ & $\%$ & $\mathbf{N}$ & $\%$ & \\
\hline Yes & 96 & 65.31 & 89 & 66.92 & 185 & 40 & 63.49 & 145 & 66.82 & 185 \\
\hline No & 51 & 34.69 & 44 & 33.08 & 95 & 23 & 36.51 & 72 & 33.18 & 95 \\
\hline Total & & & & & 280 & & & & & 280 \\
\hline $\begin{array}{l}\text { Chi-square } \\
\text { test results }\end{array}$ & \multicolumn{4}{|c|}{$\chi^{2}=0.0808565 ; \mathrm{df}=1 ; \mathrm{p}=0.77614$} & & \multicolumn{5}{|c|}{$\chi^{2}=0.2412599 ; \mathrm{df}=1 ; \mathrm{p}=0.62330$} \\
\hline
\end{tabular}

Source: own research

Individual interviews were then carried out, in which the children were requested to "substantiate" their positive response or give examples of positive outcomes of stressful situations. That request, however, proved not easy for the children from the examined age category. Many of them were not able to give any examples, knowing only perhaps "intuitively" that positive aspects of difficult situations can be found. Still, examples of benefits of stressful situations given by those children who were able to do so are very inspiring and demonstrate their ability to think and analyse:

- When you are walking along a steep cliff and it is dangerous, you can see beautiful views...

- When someone breaks their arm, he or she is later happy when their arm is well again...

- I had my tonsils removed and it was painful, but I got a big portion of icecream afterwards...

- My mum's cancer was a bad thing but the fact that she is now well is good; now she is with me at home, and before she used to work from 7.00 a.m. to 8.00 p.m.; she was terribly overworked and now she stays home with me; we talk a lot, we play together, go shopping, and I am very glad...

- The benefit of being in a difficult situation is that by being in it we learn to overcome it...

- When I was home alone for many hours I was scared, but later I learnt how to make a model plane and it made me learn something...

- When after a quarrel you make up with someone and continue to like that person, be friends with them again - this is good...

- When I go to the doctor I am scared of injection but thanks to that injection I won't be ill anymore...

- My friend Leon broke his arm on vacation and could not do anything, but I was helping him out and we got to know one another better... 
- First I had a fight, and it was wrong, but I learnt how to solve conflicts and this is good...

- When a person hits another person and apologizes for it, this is a good result...

- I do acrobatics and sometimes things don't work out as I want them to, but when I practice and improve, this is good...

- Difficult situations may teach us something... not to do bad things again...

- One can learn how to talk with people, this may prove useful because when you're grown up you have to talk with people...

The utterances quoted above indicate that some of the children positively reappraised and cognitively transformed difficult situations that they had experienced in their lives and therefore were able to notice beneficial, "valuable" aspects of stressful situations. From the above-quoted examples we can distinguish three strategies employed by children to reappraise the discussed situations. The first strategy entails personal development, the second is centred on learning vital life skills, and the third one shows appreciation of life's values. All of them are examples of children's reflections and testify to the adaptive nature of the described situations influencing the emotional, social and physiological area of the child's world. Those reflections also demonstrate that at least some of the children are not defenceless in the face of encountered problems and are able to cope with them cognitively and emotionally.

\section{Conclusion}

The presented fragment of research related to stressful situations of children in younger school age may serve as the basis for conclusion that in some of the children the developmental process of coping with difficult and stressful situations has already begun, that some of them have already entered the path on which they begin their independent search for problem-solving possibilities and check the effectiveness of employed strategies, think, analyse, turn to their environment with questions and demonstrate reflectiveness.

It is therefore extremely important not to overlook that moment in child development and offer children support in their progress. Children should be encouraged to exchange thoughts and opinions on solving difficult and stressful situations. Efforts should be concentrated on developing their problem-solving skills, including divergent thinking and skilful management of emotions in order to activate those children who already show development in that aspect and inspire those who are less reflective in that sphere. The enormous role in this process is played by family and school, i.e. parents and teachers "sensitive" to the child and his or her needs. 